\title{
Norisoboldine alleviates joint destruction in rats with adjuvant-induced arthritis by reducing RANKL, IL-6, $\mathrm{PGE}_{2}$, and MMP-13 expression
}

\author{
Zhi-feng WEI ${ }^{1}$, Xiao-lan $\mathrm{JIAO}^{1}$, Ting WANG ${ }^{1}$, Qian $\mathrm{LU}^{1}$, Yu-feng XIA ${ }^{1}$, Zheng-tao WANG ${ }^{2}$, Qing-long GUO ${ }^{3}$, Gui-xin $\mathrm{CHOU}^{2, *}$, \\ Yue DAI ${ }^{1, *}$ \\ ${ }^{1}$ State Key Laboratory of Natural Medicines, Department of Pharmacology of Chinese Materia Medica, China Pharmaceutical \\ University, Nanjing 210009, China; ${ }^{2}$ Institute of Chinese Materia Medica, Shanghai University of Traditional Chinese Medicine, \\ Shanghai 201203, China; ${ }^{3}$ Department of Physiology, China Pharmaceutical University, Nanjing 210009, China
}

\begin{abstract}
Aim: To explore the effects of norisoboldine (NOR), a major isoquinoline alkaloid in Radix Linderae, on joint destruction in rats with adjuvant-induced arthritis (AIA) and its underlying mechanisms.

Methods: AIA was induced in adult male SD rats by intradermal injection of Mycobacterium butyricum in Freund's complete adjuvant at the base of the right hind paw and tail. From d 14 after immunization, the rats were orally given NOR (7.5, 15, or 30 mg/kg) or dexamethasone $(0.5 \mathrm{mg} / \mathrm{kg})$ daily for 10 consecutive days. Joint destruction was evaluated with radiological scanning and $\mathrm{H} \& \mathrm{E}$ staining. Fibroblast-like synoviocytes (FLS) were prepared from fresh synovial tissues in the AIA rats. The expression of related proteins and mRNAs were detected by ELISA, Western blotting and RT-PCR.

Results: In AIA rats, NOR (15 and $30 \mathrm{mg} / \mathrm{kg}$ ) significantly decreased the swelling of paws and arthritis index scores, and elevated the mean body weight. NOR $(30 \mathrm{mg} / \mathrm{kg}$ ) prevented both the infiltration of inflammatory cells and destruction of bone and cartilage in joints. However, NOR (15 mg/kg) only suppressed the destruction of bone and cartilage, but did not obviously ameliorate synovial inflammation. NOR (15 and $30 \mathrm{mg} / \mathrm{kg}$ ) significantly decreased the serum levels of receptor activator of nuclear factor $\mathrm{kB}$ ligand (RANKL), IL-6, PGE 2 , and MMP-13, but not the osteoprotegerin and MMP-1 levels. The mRNA levels of RANKL, IL-6, COX-2, and MMP-13 in synovium were also suppressed. Dexamethasone produced similar effects in AIA rats as NOR did, but without elevating the mean body weight. In the cultured FLS, treatment with NOR (10 and $30 \mathrm{mmol} / \mathrm{L}$ ) significantly decreased the secretion of RANKL, IL-6, PGE 2 , and MMP-13 proteins. Furthermore, the treatment selectively prevented the activation of MAPKs, AKT and transcription factor AP-1 component c-Jun, but not the recruitment of TRAF6 or the activation of JAK2/STAT3. Treatment of the cultured FLS with the specific inhibitors of p38, ERK, AKT, and AP-1 significantly decreased the secretion of RANKL, IL-6, PGE 2 , and MMP-13 proteins.

Conclusion: NOR can alleviate joint destruction in AIA rats by reducing RANKL, IL-6, PGE 2 , and MMP-13 expression via the p38/ERK/ AKT/AP-1 pathway.
\end{abstract}

Keywords: norisoboldine; dexamethasone; rheumatoid arthritis; adjuvant-induced arthritis; joint destruction; fibroblast-like synoviocyte; receptor activator of nuclear factor KB ligand; IL-6; PGE 2 ;MP-13; COX-2; p38/ERK/AKT/AP-1 pathway

Acta Pharmacologica Sinica (2013) 34: 403-413; doi: 10.1038/aps.2012.187; published online 11 Feb 2013

\section{Introduction}

Rheumatoid arthritis (RA) is a chronic inflammatory disease characterized by synovial inflammation, erosion of bone and cartilage, and severe joint pain. Joint destruction ultimately results in reduced mobility of affected patients. RA affects

\footnotetext{
* To whom correspondence should be addressed.

E-mail yuedaicpu@hotmail.com (Yue DAl); chouguixin@yahoo.com.cn (Gui-xin CHOU)

Received 2012-10-04 Accepted 2012-12-14
}

approximately $0.5 \%$ of the adult population worldwide, and it occurs in 20-50 cases per 100000 annually ${ }^{[1-3]}$. Moreover, some diseases co-occur with RA more frequently than expected, such as cardiovascular diseases, infections and lymphoma, seriously affecting the quality of life for RA patients. The expected lifespan of RA patients is likely to be reduced by 3-10 years $^{[4]}$. In clinical settings, disease-modifying antirheumatic drugs (DMARDs) and biological agents (such as adalimumab, etanercept, infliximab, rituximab, and abatacept) are used successfully for RA management. However, there are many 
problems to be solved, especially in terms of cost and patients increased susceptibility to infection as well as the existence of low-responders to these treatments. New therapeutic agents with high efficiency and few side effects are expected. In past decades, some active components derived from traditional Chinese medicines, such as total glucosides from the roots of Tripterygium wilfordii Hook F or Paeonia lactiflora Palla, and sinomenine from the stems of Sinomenium acutum (Thunb) Rehd et Wils, have been successfully developed as remedies for RA in China ${ }^{[5-7]}$.

Radix Linderae, the dry root of Lindera aggregata, is frequently used in traditional Chinese medicine. It contains a series of components, including alkaloids, volatile oils and sesquiterpene esters. The total alkaloid components have previously been demonstrated to be a potential therapeutic agent for $\mathrm{RA}^{[8]}$. NOR, the major isoquinoline alkaloid in Radix Linderae, has a proven ability to prevent lipopolysaccharideinduced in vitro activation of macrophages and the resultant production of pro-inflammatory cytokines by down-regulating the activation of MAPKs signaling pathway and inhibiting the production of IL-6 in fibroblast-like synoviocytes (FLS) from rats with adjuvant-induced arthritis (AIA) through the PKC/ MAPK/NF-KB-p65/CREB pathways ${ }^{[9,10]}$. The present study was performed to explore the effects of NOR on AIA in rats with an emphasis on joint destruction mechanisms.

\section{Materials and methods}

\section{Animals}

Male Sprague-Dawley rats, weighing between 180 and $220 \mathrm{~g}$, were purchased from Shanghai SLAC Laboratory Animal Co Ltd (Shanghai, China). They were fed standard laboratory chow with tap water ad libitum, and the husbandry room was maintained at $22 \pm 2{ }^{\circ} \mathrm{C}$ with a $12 \mathrm{~h}$ light: $12 \mathrm{~h}$ dark cycle. Animal experiments were conducted under the guidelines of current ethical regulations for institutional animal care and use at China Pharmaceutical University.

\section{Chemicals and reagents}

NOR ( $>98 \%$, Figure 1A) was obtained from Radix Linderae by the authors, and the structure was established by comparison of its spectral data (UV, IR, MS, ${ }^{1} \mathrm{H}-$, and ${ }^{13} \mathrm{C}-\mathrm{NMR}$ ) with previously reported data ${ }^{[11]}$. Dexamethasone (DEX) was purchased from Zhejiang Xianju Pharmaceutical Co Ltd (Taizhou, China), and Mycobacterium butyricum was obtained from Becton Drive Co Ltd (New Jersey, NY, USA). Rat RANKL, OPG, IL-6, PGE 2 MMP-1, and MMP-13 ELISA kits were all purchased from R\&D systems (Minneapolis, MN, USA), rat IL-1 $\beta$ was purchased from PeproTech Int (Connecticut, USA), and Collagenase Type II was purchased from Gibco BRL (Grand Island, NY, USA). SB203580 (a specific inhibitor of p38 MAPK), U0126 (a specific inhibitor of ERK), triciribine (a<smiles>COc1cc2c(cc1O)CC1NCCC3=CC(O)=C(O)C3=C21</smiles>
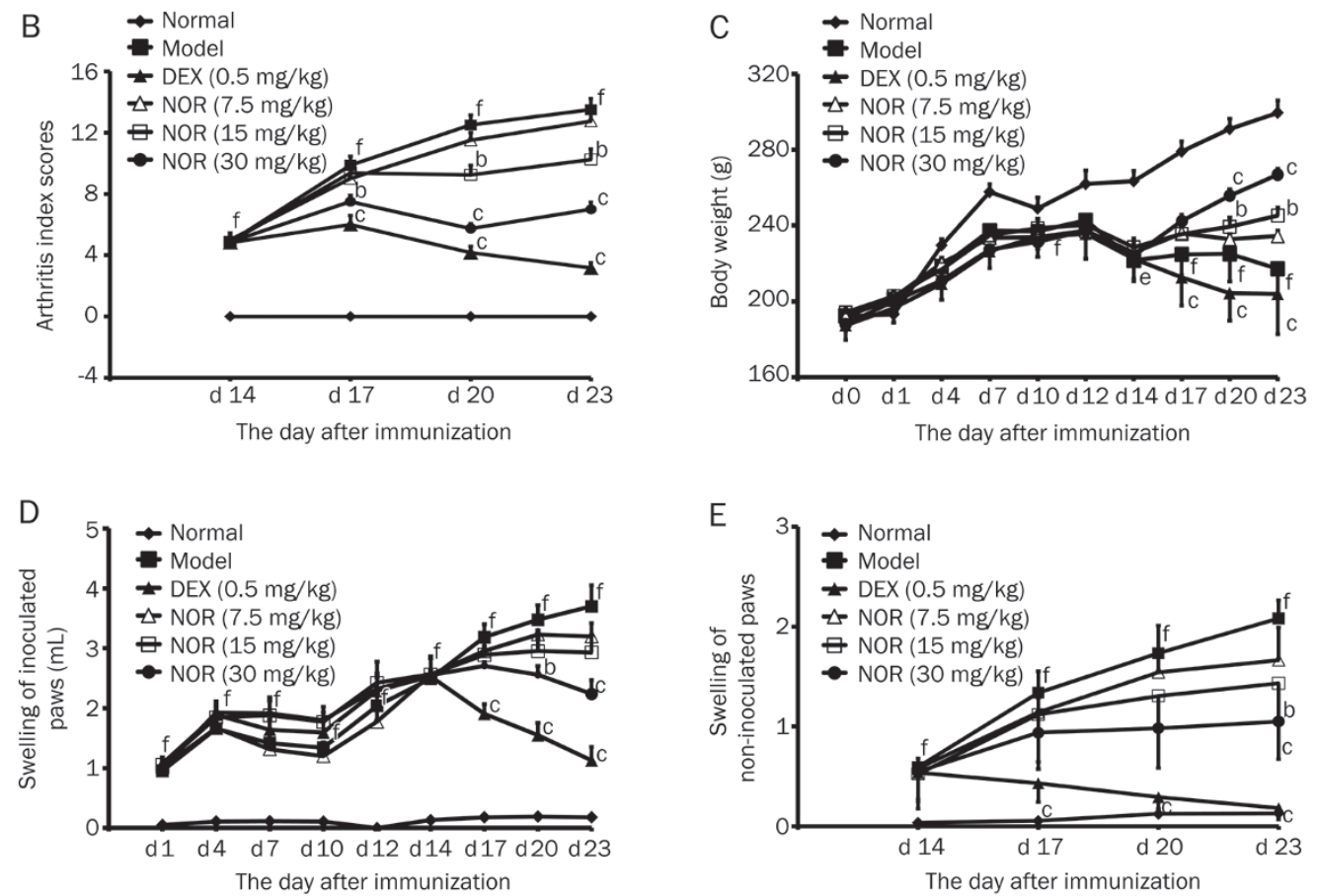

Figure 1. Therapeutic effects of norisoboldine (NOR) and dexamethasone (DEX) on adjuvant-induced arthritis (AIA) in rats. From d 14 after the intradermal injection of Freund's complete adjuvant, rats were orally given NOR (7.5, 15, and $30 \mathrm{mg} / \mathrm{kg})$, DEX (0.5 mg/ $\mathrm{kg})$ and diluent alone for ten consecutive days. (A) Chemical structure of norisoboldine. (B) Effects of NOR and DEX on the arthritis index scores of AIA rats. (C) Effects of NOR and DEX on mean body weights of AIA rats. The body weights of rats were determined on indicated days. (D) Effects of NOR and DEX on the swelling of inoculated and non-inoculated paws of AIA rats. Paw volumes were measured using a plethysmometer on indicated days. Mean \pm SEM. $n=8$. ${ }^{b} P<0.05$, ${ }^{c} P<0.01$ vs model. ${ }^{f} P<0.01$ vs normal. 
specific inhibitor of AKT), and GAPDH monoclonal antibody were purchased from KangChen Bio-tech (Shanghai, China). Curcumin (a specific inhibitor of AP-1) was purchased from Sigma Chemical Co (St Louis, MO, USA). TRAF6, JAK2, p-JAK2, STAT3, p-STAT3, AKT, p-AKT, and p-c-Jun monoclonal antibodies were purchased from Bioworld (Georgia, USA). Enhanced chemiluminescent (ECL) plus reagent kits and peroxidase-conjugated secondary antibody were purchased from MultiSciences (Hangzhou, China). The other chemicals and reagents used were of analytical grade.

\section{Induction of AIA and administration of NOR}

Experimental arthritis was induced by an intradermal injection with $0.1 \mathrm{~mL}$ of $10 \mathrm{mg} / \mathrm{mL}$ Mycobacterium butyricum in Freund's complete adjuvant at the base of the right hind paw and the tail of the rats ${ }^{[12-14]}$. On d 14 after immunization, rats were assigned randomly to one of the following six groups: the normal group (treatment with $0.5 \% \mathrm{CMC}-\mathrm{Na}$, the vehicle), the model group (treatment with $0.5 \% \mathrm{CMC}-\mathrm{Na}$, the vehicle), three NOR groups (treatment with 7.5, 15, and $30 \mathrm{mg} / \mathrm{kg}$ ) and the DEX group (treatment with $0.5 \mathrm{mg} / \mathrm{kg}$ ). NOR and DEX were administered orally for 10 consecutive days, from $\mathrm{d} 14$ to d 23. Normal and model rats were orally given an equal volume of vehicle solution on the same schedule.

\section{AIA measurements}

The rats' body weights, arthritis index scores and paw volumes were measured. Arthritis index scores were assigned to each joint by observers blinded to the groups. Scoring was performed on a $0-4$ scale, where $0=$ no swelling or erythema, $1=$ slight swelling and/or erythema, $2=$ low to moderate edema, $3=$ pronounced edema with limited joint usage, and $4=$ excess edema with joint rigidity. The volumes of hind paws were determined using a paw volume plethysmometer.

\section{Radiological scanning}

On d 24 after immunization, the joints of non-inoculated hind paws of AIA rats, which had been given a general anaesthetic of ether, were X-rayed using a radiograph equipped with a direct digital imaging system. The destruction of ankle joints was scored on a scale of $0-3$, where $0=$ no joint erosion, $1=$ mild joint erosion, $2=$ moderate joint erosion, and $3=$ severe joint erosion. Mean scores were calculated for each rat.

\section{Histological analysis}

After radiological scanning, rats were sacrificed with ether anesthesia, and the hind paws of the non-inoculated sides were harvested for analysis. Formaldehyde-fixed hind paws were decalcified with a solution containing $10 \%$ ethylenediaminetetraacetic acid, and ankle tissues were then sectioned, embedded in paraffin, and sliced for hematoxylin and eosin (H\&E) staining. Several parameters were used in the histological scoring of the rat ankle joints. Tissue sections were scored individually for infiltration of inflammatory cells, synovial hyperplasia, pannus formation, cartilage and bone erosion on a scale of $0-3(0=$ none, $1=$ mild, $2=$ moderate, and $3=$ severe $)$ by a pathologist blinded to the experimental groups. Then the mean of all scores was calculated.

\section{Measurement of RANKL, OPG, IL-6, PGE 2 , MMP-1, and MMP-13 levels in serum}

In brief, blood was collected from rats on d 24, after they had been sacrificed with ether anesthesia. After centrifugation for $20 \mathrm{~min}$ at a speed of 3000 rounds per minute, sera were obtained. The levels of RANKL, OPG, IL-6, PGE 2 MMP-1, and MMP-13 were detected using ELISA kits according to the manufacturer's instructions.

\section{Measurement of RANKL, IL-6, COX-2, and MMP-13 mRNA levels in synovial membranes}

The synovial tissue samples were obtained from the AIA rats and mRNA levels of RANKL, IL-6, COX-2, and MMP-13 were assessed by reverse-transcription polymerase chain reaction (RT-PCR). Total RNA was extracted with TRIzol according to the manufacturer's instructions. The concentration was determined by spectrophotometric optical density measurement at $260 \mathrm{~nm}$ and $280 \mathrm{~nm}$. RNA (2 $\mu \mathrm{g})$ was reversetranscribed with M-MLV reverse transcriptase. A master mix containing the reaction buffer, dNTPs, Taq polymerase, and $2 \mu \mathrm{L}$ cDNA in a $25 \mu \mathrm{L}$ reaction mixture was transferred to different PCR tubes, and $\beta$-actin served as a normalization control. The PCR products were determined using 1.5\% agarose gel electrophoresis and Goldview staining. Images of the gels were analyzed using the Quantity One software (BioRad, CA, USA) by comparing the relative density of objective straps and $\beta$-actin. Gene-specific primers used in RT-PCR were as follows: RANKL forward, 5'-ACTTTCGAGCGCAGATGGAT-3', reverse, 5'-CACATCGAGCCACGAACCT-3'; IL-6 forward, 5'-GACAAAGCCAGAGTCCTTCA-3', reverse, 5' ${ }^{\prime}$-ACTAGGTTTGCCGAGTAGAC-3'; COX-2 forward, 5'-ACTTGCTCACTTTGTTGAGTCATTC-3'; reverse, 5'-TTTGATTAGTACTGTAGGGTTAATG-3'; MMP-13 forward, 5' -AGACCTCCAGTTTGCAGAGCGCGT-3', reverse, 5'-ACCCACATCAGGAACCCCGCAT-3'; $\beta$-actin forward, 5'-AGCCATGTACGTAGCCATCC-3', reverse, 5'-CTCTCAGCAGTGGTGGTGAA-3'.

\section{Cell culture}

Fresh synovial tissues were obtained from AIA rats and washed twice with PBS. The synovium was minced and digested in $2 \mathrm{~mL}$ of DMEM supplemented with $0.4 \%$ collagenase Type II, 10\% newborn calf serum (NCS), $100 \mathrm{U} / \mathrm{mL}$ penicillin and $100 \mu \mathrm{g} / \mathrm{mL}$ streptomycin in a humidified $5 \%$ $\mathrm{CO}_{2}$-containing atmosphere at $37^{\circ} \mathrm{C}$ for $2 \mathrm{~h}$. Each synovium was then centrifugated for $10 \mathrm{~min}$ at a speed of 2000 rounds per minute. The precipitate was digested in $0.25 \%$ trypsin for $20 \mathrm{~min}$ and centrifugated for $10 \mathrm{~min}$ at a speed of 1200 rounds per minute. After filtration, the precipitates were incubated in DMEM with $10 \%$ NCS, $100 \mathrm{U} / \mathrm{mL}$ penicillin, and $100 \mu \mathrm{g} / \mathrm{mL}$ streptomycin and maintained at $37^{\circ} \mathrm{C}$ in $5 \% \mathrm{CO}_{2}$ humidified air. After $24 \mathrm{~h}$, the adherent cells (fibroblast-like synoviocytes, FLS) were cultured in the fresh medium, and non-adherent 
cells were removed $^{[15,16]}$. The following experiments were performed using cells within passages 3-5.

\section{Cell viability assay}

The cell viability of FLS was detected using the MTT assay. Briefly, FLS $\left(1 \times 10^{5}\right.$ cells $\left./ \mathrm{mL}\right)$ were plated into 96 -well plates and then incubated for $12 \mathrm{~h}$ at $37^{\circ} \mathrm{C}$ and $5 \% \mathrm{CO}_{2}$. After treatment with various concentrations of $\operatorname{NOR}(3,10$, and 30 $\mu \mathrm{mol} / \mathrm{L})$ in the presence or absence of IL-1 $\beta(10 \mathrm{ng} / \mathrm{mL})$ for $72 \mathrm{~h}$, cells were treated with $20 \mu \mathrm{L}$ of MTT $(5 \mathrm{mg} / \mathrm{mL})$ and incubated for an additional $4 \mathrm{~h}$. Subsequently, the supernatants were removed, and the formazone crystals were dissolved using $150 \mu \mathrm{L}$ of DMSO. The optical absorbance at $570 \mathrm{~nm}$ was read with a Model 1500 Multiskan spectrum microplate reader (Thermo, Waltham, MA, USA).

\section{Western blotting}

TRAF6, JAK2, p-JAK2, STAT3, p-STAT3, AKT, p-AKT, p-cJun, and GAPDH were analyzed by Western blotting. FLS $\left(1 \times 10^{5}\right.$ cells $\left./ \mathrm{mL}\right)$, cultured in flasks until $90 \%$ confluent, were pre-treated with $\operatorname{NOR}(3,10$, and $30 \mu \mathrm{mol} / \mathrm{L})$ for $24 \mathrm{~h}$ and then stimulated with IL-1 $\beta(10 \mathrm{ng} / \mathrm{mL})$ for the indicated time. Cells were washed twice with ice-cold PBS buffer ( $\mathrm{pH} 7.2)$. Proteins were extracted with lysis buffer $(50 \mathrm{mmol} / \mathrm{L}$ Tris- $\mathrm{HCl}, 150$ $\mathrm{mmol} / \mathrm{L} \mathrm{NaCl}, 0.02 \% \mathrm{NaN}_{3}, 1 \% \mathrm{NP}-40$ ) for $15 \mathrm{~min}$ on ice. The cytosol and nuclear extracts were harvested after centrifugation at 12000 rounds per minute for $10 \mathrm{~min}$. The protein concentrations were determined by the Bradford assay. Samples were separated using a 10\% acrylamide gel and SDS-PAGE and transferred to PVDF membranes. Membranes were blocked for $1 \mathrm{~h}$ at room temperature with $5 \%$ nonfat milk in $0.1 \%$ PBS-Tween 20 (PBST) and then incubated with JAK2, p-JAK2, STAT3, p-STAT3, AKT, p-AKT, p-c-Jun, or GAPDH antibodies. They were then washed three times with PBST buffer and incubated with peroxidase-conjugated secondary antibodies for $1 \mathrm{~h}$ at room temperature. The bands were visualized using film exposure with ECL substrate.

\section{RANKL, IL-6, PGE 2 , and MMP-13 assay in the supernatants of} FLS

FLS $\left(1 \times 10^{5}\right.$ cells $\left./ \mathrm{mL}\right)$ were seeded into 96-well plates and then treated with SB203580 (a specific inhibitor of p38 MAPK, 5 and $10 \mu \mathrm{mol} / \mathrm{L}$ ), U0126 (a specific inhibitor of ERK, 5 and $10 \mu \mathrm{mol} / \mathrm{L}$ ), triciribine (a specific inhibitor of AKT, 5 and 10 $\mu \mathrm{mol} / \mathrm{L}$ ), curcumin (a specific inhibitor of AP-1, 5, and 10 $\mu \mathrm{mol} / \mathrm{L})$ or $\operatorname{NOR}(3,10$, and $30 \mu \mathrm{mol} / \mathrm{L})$ in the presence or absence of IL-1 $\beta$ (10 ng/mL) for the indicated times. Then, the culture supernatants were collected, and levels of RANKL, IL-6, PGE 2 , and MMP-13 were measured using ELISA kits according to the manufacturer's instructions.

\section{Statistical analysis}

Data are presented as the mean \pm SEM. Significant differences were assessed by one-way analysis of variance (ANOVA) followed by a post hoc Tukey's test. $P$ values less than 0.05 were accepted as significant.

\section{Results}

\section{Therapeutic effects of NOR on rat AIA}

To evaluate the therapeutic effects of NOR on rat AIA, rats were immunized by an intradermal injection of Freund's complete adjuvant. On d 14, they were divided into various groups and orally administered with NOR or DEX in $0.5 \%$ CMC-Na (vehicle).

Arthritis index scores were determined based on a scale of 0-4 for each ankle. The mean arthritis index score for the model group suggests that secondary arthritis onset began after $\mathrm{d} 10$ (Figure 1B). NOR (15 and $30 \mathrm{mg} / \mathrm{kg}$ ) and DEX (0.5 mg/kg) treatments markedly reduced mean arthritis index scores by attenuating the severity of joint swelling and erythema during the observation period.

Animal body weight gain is usually considered a good index of both anti-inflammatory and immunosuppressive effects of the drugs tested in the AIA model. In this study, the mean body weights of rats in all groups increased during the initial $7 \mathrm{~d}$ after adjuvant induction. Following the onset of secondary arthritis, the mean body weights of rats immunized with Freund's complete adjuvant gradually decreased. In contrast, the mean body weights of rats that did not receive adjuvant continued to increase throughout this period. NOR (15 and 30 $\mathrm{mg} / \mathrm{kg}$ ) treatments showed significant prevention of the loss of body weight between d 14 and d 23. In contrast, DEX did not affect body weight loss, although it effectively improved the clinical scores of AIA rats (Figure 1C).

Swelling of paws was also measured using a plethysmometer to quantify and compare inflammation among groups. As shown in Figure 1D, adjuvant injection resulted in an acute inflammatory phase of swelling in the inoculated paws and an autoimmune phase of swelling in both inoculated and noninoculated paws after d 10. NOR (30 mg/ kg) and DEX (0.5 $\mathrm{mg} / \mathrm{kg}$ ) markedly reduced the volumes of both inoculated and non-inoculated paws.

\section{Effects of NOR on the joint destruction of AIA rats}

The protective effect of NOR on joint destruction at noninoculated sides of AIA rats was evaluated using radiological scanning. The results revealed that rats in the model group presented dramatic destruction in joints; however, the NOR (15 and $30 \mathrm{mg} / \mathrm{kg})$ and DEX $(0.5 \mathrm{mg} / \mathrm{kg})$ treatments showed significant inhibition of destruction. The inhibitory percentage of NOR (30 mg/ $\mathrm{kg}$ ) reached $50.0 \%$, which was higher than that of DEX $(0.5 \mathrm{mg} / \mathrm{kg})$ (Figure 2A).

Histological assessment of tissue sections was also performed to detect the changes in rat ankles on d 24 after the induction of AIA. The ankle joints of rats in the model group presented pronounced infiltration of granulocytes and mononuclear cells, synovial hyperplasia, pannus formation, and erosion of bone and cartilage as compared with the normal group. As shown in Figure 2B, NOR (30 mg/kg) and DEX $(0.5 \mathrm{mg} / \mathrm{kg})$ treatments prevented both the infiltration of inflammatory cells and destruction of bone and cartilage. At $15 \mathrm{mg} / \mathrm{kg}$, NOR could suppress the destruction of bone and cartilage in joints by $30.0 \%$ but could not obviously ameliorate 

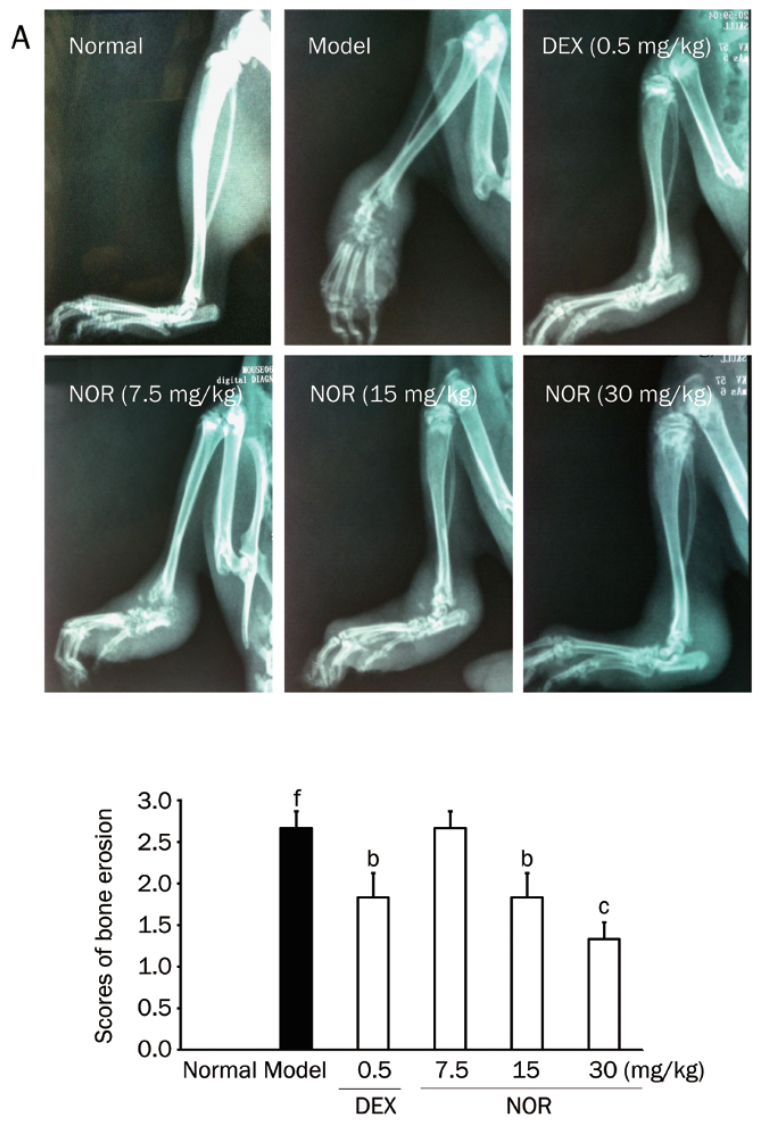
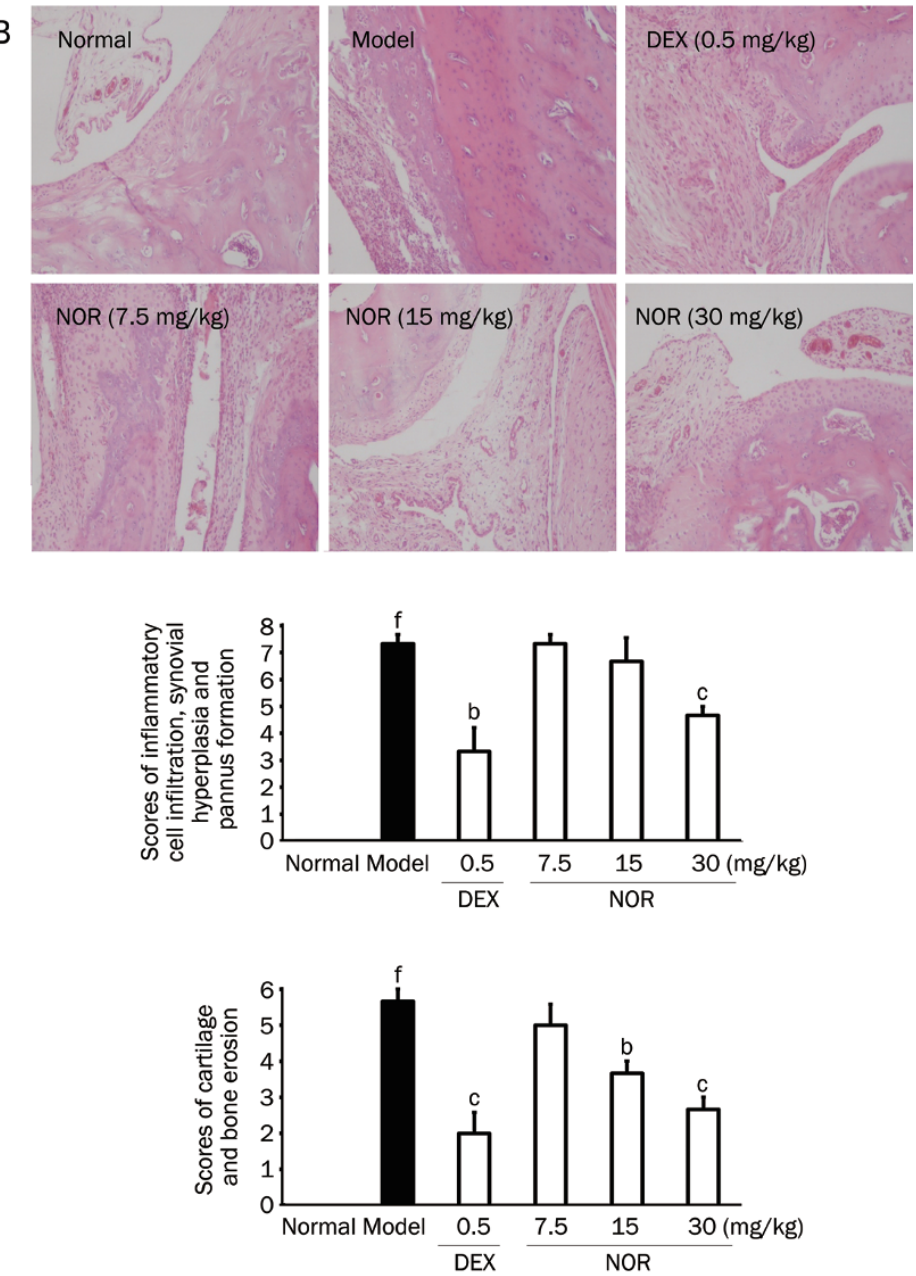

Figure 2. Effects of norisoboldine (NOR) and dexamethasone (DEX) on joint destruction in adjuvant-induced arthritis (AIA) rats. (A) On d 24 after the intradermal injection of adjuvant, $\mathrm{X}$-rays were taken after the rats were given a general anaesthetic of ether. The degree of joint erosion on the radiographs was scored on a scale of $0-3$ as described in the Materials and methods section. (B) On d 24 after the intradermal injection of adjuvant, the ankle joints of AIA rats were collected. Histological changes were detected using H\&E staining. Pathohistological grades were evaluated according to the infiltration of inflammatory cells, synovial hyperplasia, pannus formation, cartilage and bone erosion. The histological scores of all groups were summarized (original magnification $\times 200$ ). Mean \pm SEM. $n=8 .{ }^{b} P<0.05,{ }^{C} P<0.01$ vs model. ${ }^{f} P<0.01$ vs normal.

synovial inflammation.

Effects of NOR on levels of RANKL and OPG in the serum and synovial membranes of AIA rats

The RANKL/OPG system plays an important role in joint destruction in RA by regulating the differentiation and function of osteoclasts ${ }^{[17,18]}$. To elucidate the mechanisms responsible for the joint-protective action of NOR in AIA rats, its effects on the levels of RANKL and OPG were assessed. As Figure 3A shown, the serum levels of RANKL in AIA model rats were dramatically increased by approximately four-fold, but OPG levels in model rats were only slightly increased. NOR (15 and $30 \mathrm{mg} / \mathrm{kg})$ and DEX (0.5 mg/ kg) treatments markedly decreased serum levels of RANKL but had little effect on serum levels of OPG, leading to a significant decrease of RANKL/OPG ratio. Moreover, the mRNA levels of RANKL in the synovial membranes of AIA model rats were also increased, and NOR (15 and $30 \mathrm{mg} / \mathrm{kg}$ ) and DEX (0.5 $\mathrm{mg} / \mathrm{kg}$ ) treatments suppressed the mRNA levels of RANKL in synovial membranes (Figure 3B).

Effects of NOR on levels of IL-6, PGE 2 , MMP-1, and MMP-13 in serum and synovial membranes of AIA rats

Data have shown that IL-6, PGE 2 , MMP-1, and MMP-13 are crucial in association with the joint destruction of RA. MMPs and $\mathrm{PGE}_{2}$ could directly degrade collagen and proteoglycan in cartilage and bone matrix, respectively. The proinflammatory cytokine IL-6 is able to significantly up-regulate both the expressions of MMPs and $\mathrm{PGE}_{2}$ in chondrocytes and fibroblasts of $\mathrm{RA}^{[19]}$. As Figure $4 \mathrm{~A}$ shown, the serum levels of IL-6, PGE 2 , MMP-1, and MMP-13 in AIA model rats were all dramatically increased; NOR (15 and $30 \mathrm{mg} / \mathrm{kg}$ ) and DEX $(0.5 \mathrm{mg} / \mathrm{kg})$ treatments markedly decreased IL-6, PGE 2 and MMP-13 levels in serum but had little effect on MMP-1 levels. 

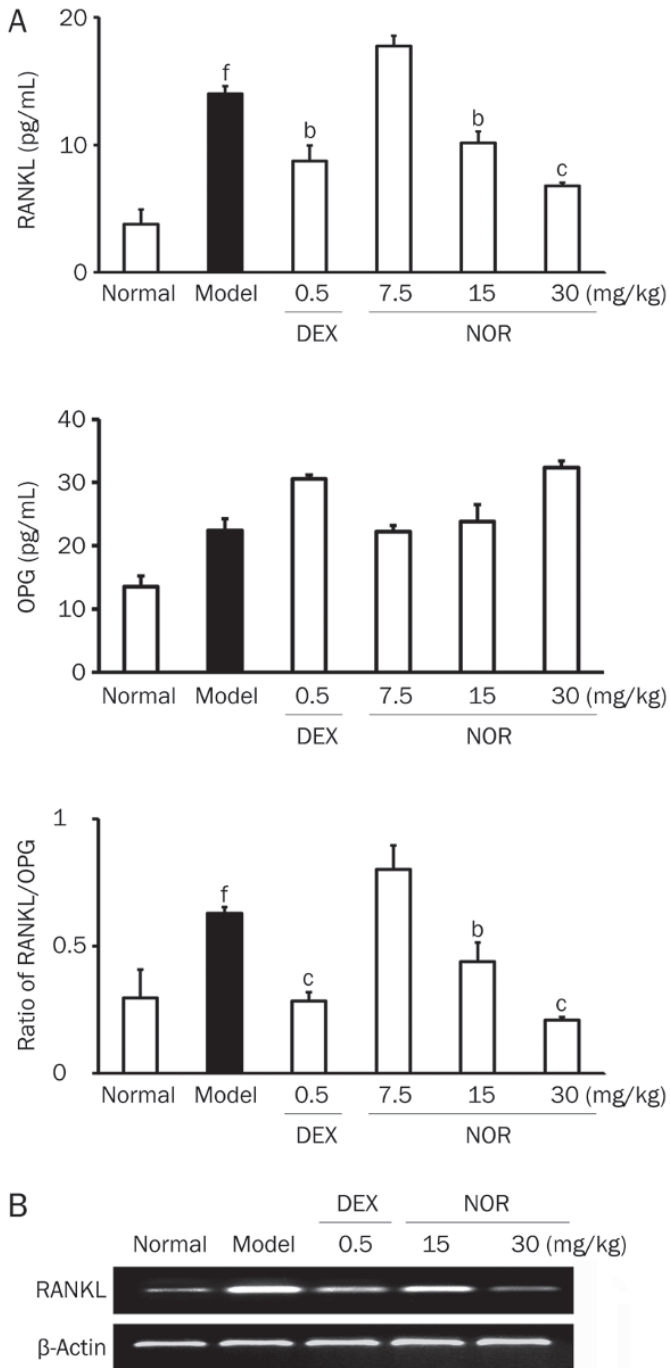

Figure 3. Effects of norisoboldine (NOR) on the levels of RANKL and OPG in sera and synovial membranes of adjuvant-induced arthritis (AIA) rats. On d 24 after the intradermal injection of adjuvant, the blood and synovial membranes of AIA rats were collected. (A) The levels of RANKL and OPG in serum were determined by ELISA. (B) The mRNA levels of RANKL in synovial membranes were determined by RT-PCR. Mean \pm SEM. $n=8$. ${ }^{\mathrm{b}} P<0.05,{ }^{\mathrm{c}} P<0.01$ vs model. ${ }^{\mathrm{f}} P<0.01$ vs normal.

Furthermore, NOR (15 and $30 \mathrm{mg} / \mathrm{kg})$ and DEX $(0.5 \mathrm{mg} / \mathrm{kg})$ also significantly down-regulated the mRNA levels of IL-6, COX-2 (the rate-limiting enzyme of $\mathrm{PGE}_{2}$ ) and MMP-13 in the synovial membranes of AIA rats (Figure 4B).

\section{Effects of NOR on IL-1 $\beta$-induced RANKL, PGE 2 , and MMP-13} expressions in FLS from AIA rats

It has been demonstrated that proliferative FLS in the synovial membranes of RA-affected joints participates in both the propagation of inflammation and joint destruction, as they can produce large amounts of proinflammatory mediators and enzymes, including IL-1, IL-6, TNF- $\alpha, \mathrm{PGE}_{2}$, and MMPs ${ }^{[20-22]}$. In this study, primary FLS from AIA rats were isolated and cultured to identify potential causes for the inhibitory action of
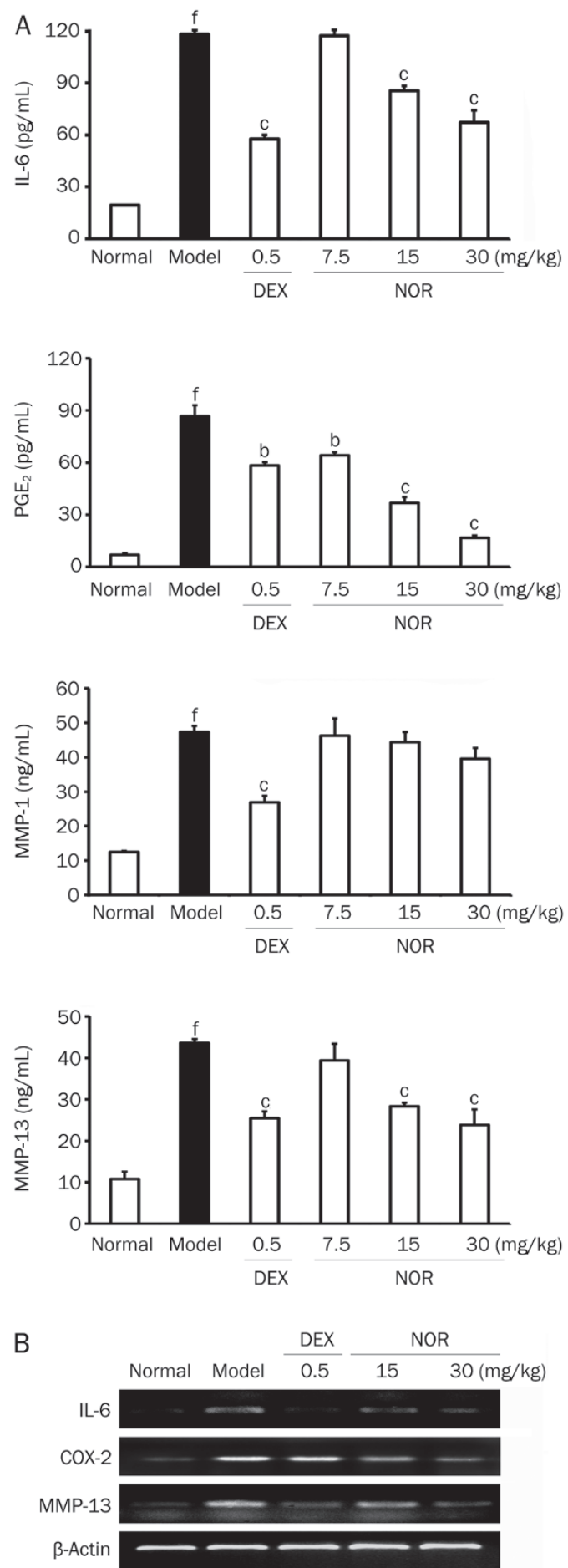

Figure 4. Effects of norisoboldine (NOR) on the levels of IL-6, PGE COX-2, MMP-1, and MMP-13 in sera and synovial membranes of adjuvantinduced arthritis (AIA) rats. On d 24 after the intradermal injection of adjuvant, the blood and synovial membranes of AIA rats were collected. (A) The levels of IL-6, PGE 2 , MMP-1, and MMP-13 in the sera were determined by ELISA. (B) The mRNA levels of IL-6, COX-2, and MMP-13 in synovial membranes were determined by RT-PCR. Mean \pm SEM. $n=8$. ${ }^{b} P<0.05$, ${ }^{\mathrm{c}} P<0.01$ vs model. ${ }^{\mathrm{f}} P<0.01$ vs normal.

NOR on the expression of RANKL, IL-6, PGE 2 , and MMP-13. In a previous study we demonstrated that NOR could sup- 

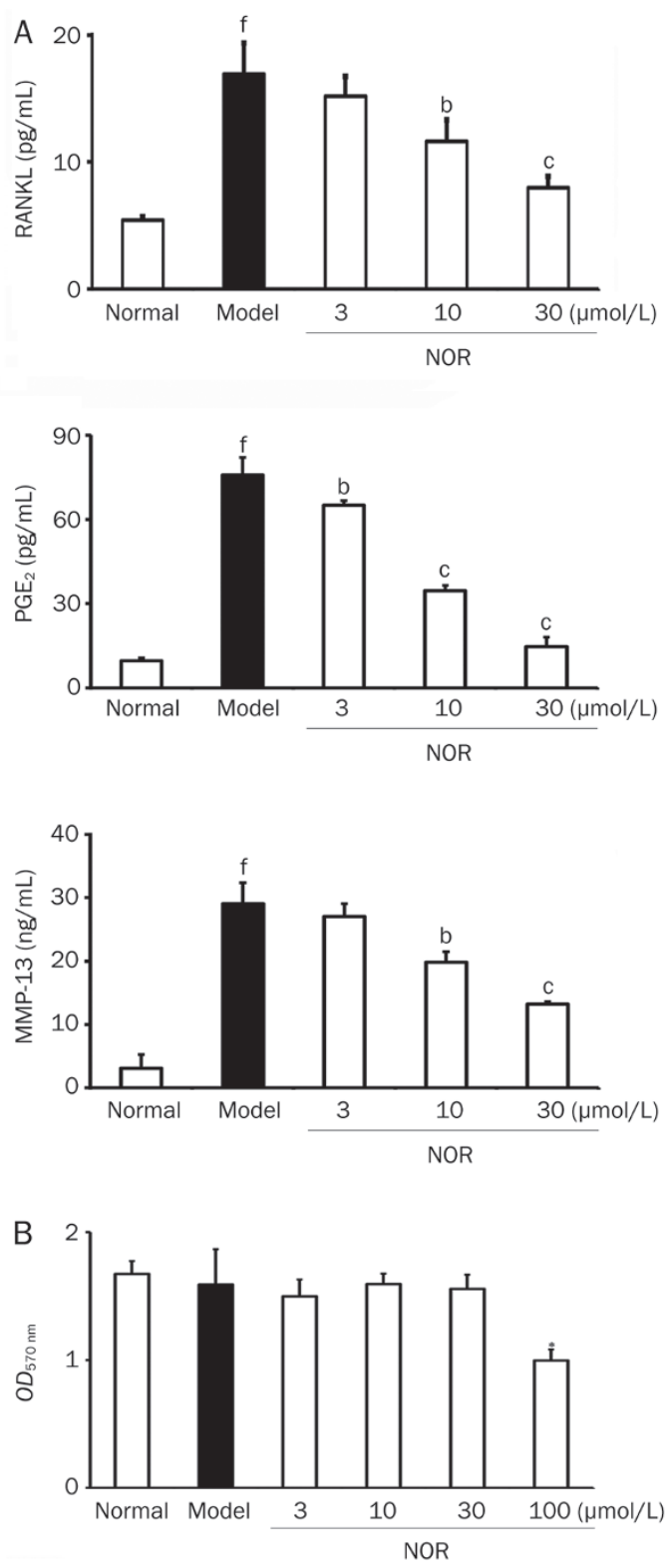

Figure 5. Effects of norisoboldine (NOR) on IL-1ß-induced RANKL, $\mathrm{PGE}_{2}$, and MMP-13 expressions in fibroblast-like synoviocytes (FLS) from adjuvant-induced arthritis rats. (A) FLS were treated with NOR $(3,10$, and $30 \mu \mathrm{mol} / \mathrm{L})$ in the presence or absence of IL-1 $13 \mathrm{ng} / \mathrm{mL})$ for $72 \mathrm{~h}$, and the secretion of RANKL was determined by ELISA. FLS were treated with $\operatorname{NOR}(3,10$, and $30 \mu \mathrm{mol} / \mathrm{L})$ in the presence or absence of IL-1 $\beta$ (10 $\mathrm{ng} / \mathrm{mL}$ ) for $24 \mathrm{~h}$, and the secretion of $\mathrm{PGE}_{2}$ and MMP-13 was determined by ELISA. (B) FLS were treated with $\operatorname{NOR}(3,10$, and $30 \mu \mathrm{mol} / \mathrm{L})$ in the presence or absence of IL-1 $(10 \mathrm{ng} / \mathrm{mL})$ for $72 \mathrm{~h}$. Cell viability was determined by the MTT assay. Mean \pm SEM. $n=3$. ${ }^{\mathrm{b}} P<0.05,{ }^{\mathrm{c}} P<0.01$ vs model. ${ }^{\mathrm{f}} P<0.01$ vs normal.

press the levels of IL- 6 in FLS that were stimulated by IL-1 $\beta^{[10]}$. In the present study, the results further revealed that IL-1 $\beta$ (10 $\mathrm{ng} / \mathrm{mL}$ ) stimulation induced a significant increase in the levels of RANKL, PGE ${ }_{2}$ and MMP-13. NOR (10 and $\left.30 \mu \mathrm{mol} / \mathrm{L}\right)$ treatment exhibited a notable down-regulation of RANKL, $\mathrm{PGE}_{2}$ and MMP-13 (Figure 5A). At $30 \mu \mathrm{mol} / \mathrm{L}$, the inhibitory percentages of NOR on protein levels of RANKL, $\mathrm{PGE}_{2}$ and MMP-13 were $46.7 \%, 80.6 \%$, and $54.6 \%$, respectively.

To exclude the possibility that the effects on activated FLS were due to cytotoxicity, the effects of NOR on the viability of FLS in the presence of IL-1 $\beta(10 \mathrm{ng} / \mathrm{mL})$ were detected using an MTT assay. The results showed that NOR-induced cytotoxicity was negligible under a concentration of $100 \mu \mathrm{mol} / \mathrm{L}$ (Figure 5B).

\section{Effects of NOR on IL-1ß-induced TRAF6 expression in FLS from AIA rats}

IL-1 $\beta$ functions by binding to its receptor IL-1R, resulting in the recruitment of TRAF6. The latter has been implicated in directing the signals from representative members of a diverse array of receptor families ${ }^{[23]}$, and it induces multiple activations of downstream signaling pathways. In this study, IL-1 $\beta$ $(10 \mathrm{ng} / \mathrm{mL})$ stimulation led to increased expression of TRAF6 in FLS, with a peak at 5 min (data not shown). NOR pretreatment for $24 \mathrm{~h}$ failed to alter TRAF6 expression (Figure 6), suggesting that the inhibition of cytokines expression by NOR might not be mediated through interfering with the initial signal.
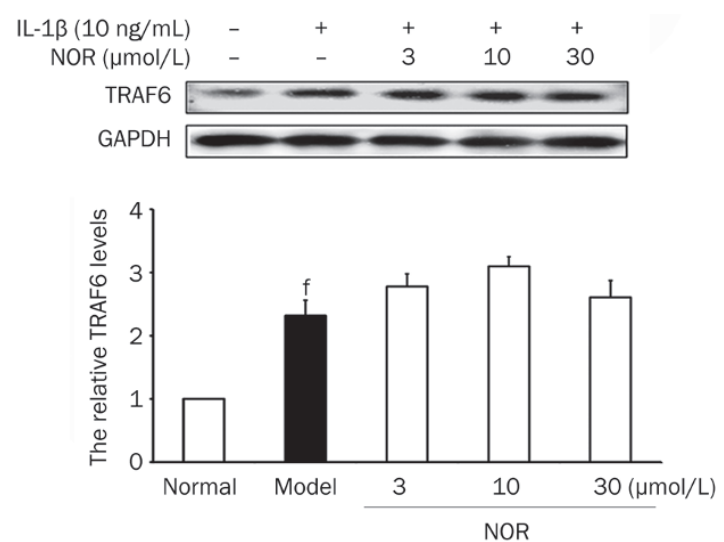

Figure 6. Effects of norisoboldine (NOR) on IL-1 $\beta$-induced TRAF6 expression in fibroblast-like synoviocytes (FLS) from adjuvant-induced arthritis rats. FLS were pre-treated with $\operatorname{NOR}(3,10$, and $30 \mu \mathrm{mol} / \mathrm{L})$ for $24 \mathrm{~h}$ and then stimulated with $\mathrm{IL}-1 \beta(10 \mathrm{ng} / \mathrm{mL})$ for $5 \mathrm{~min}$. The protein levels of TRAF6 were determined by Western blotting. Mean \pm SEM. $n=3$. ${ }^{\mathrm{f}} P<0.01$ vs normal.

Effects of NOR on IL-1ß-induced activation of JAK2/STAT3 and AKT in FLS from AIA rats

It is widely accepted that MAPKs, JAK2/STAT3, and AKT, which are located downstream of the TRAF6 signaling complex, play important roles in the IL- $1 \beta$-induced activation of FLS and the subsequent expressions of proinflammatory cytokines by triggering a cascade reaction ${ }^{[23-26]}$. In previous studies, we have demonstrated that NOR could significantly down-regulate the IL-1 $\beta$-induced activation of p38 MAPK and ERK in FLS ${ }^{[10]}$. In the present study, we further assessed the action of NOR on the activation of JAK2, STAT3, and 

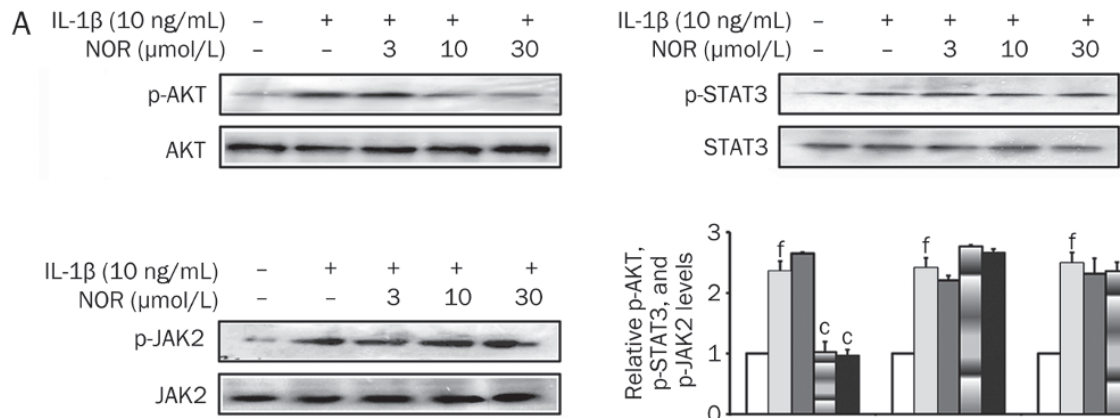

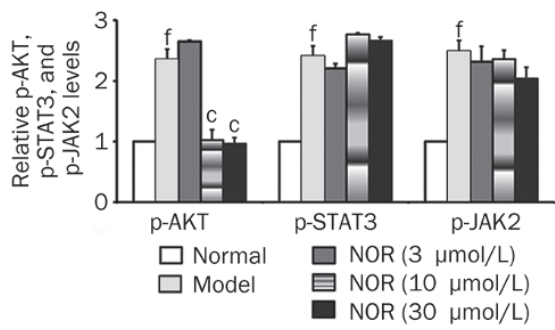

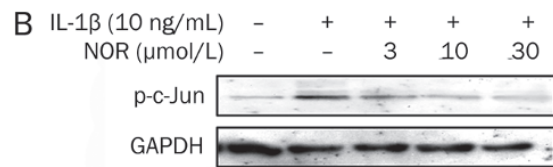

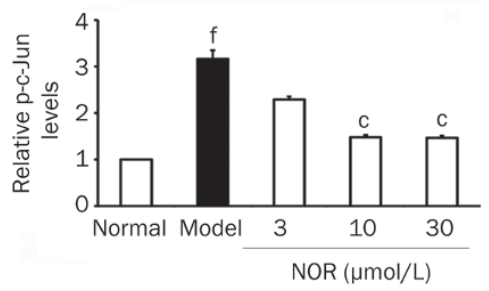

Figure 7. Effects of norisoboldine (NOR) on IL-1ß-induced activation of JAK2/STAT3, AKT, and transcription factor AP-1 in fibroblast-like synoviocytes (FLS) from adjuvant-induced arthritis rats. (A) FLS were pre-treated with NOR (3, 10, and $30 \mu \mathrm{mol} / \mathrm{L})$ for $24 \mathrm{~h}$ and then stimulated with IL-1 $\mathrm{B}(10 \mathrm{ng} / \mathrm{mL})$ for 15 min. The JAK2, STAT3, AKT, p-JAK2, p-STAT3, and p-AKT were analyzed by Western blotting. (B) FLS were pre-treated with NOR (3, 10, and $30 \mu$ mol/L)

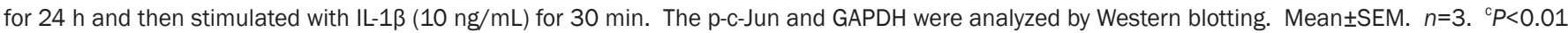
vs model. ${ }^{\mathrm{f}} \mathrm{P}<0.01$ vs normal.

AKT. As shown in Figure 7A, NOR significantly suppressed IL-1 $\beta$-induced phosphorylation of AKT in FLS from AIA rats by $59.8 \%$ and $62.2 \%$ at concentrations of 10 and $30 \mu \mathrm{mol} / \mathrm{L}$, respectively. However, it did not affect the phosphorylation states of JAK2 and STAT3.

\section{Effects of NOR on IL-1ß-induced activation of transcription factor} AP-1 in FLS from AIA rats

AP-1, a family of transcription factors, is an important regulator of proinflammatory cytokine transcription. It can be activated by MAPKs, JAK2/STAT3, AKT, and other signaling proteins. The results showed that IL- $1 \beta$ stimulation led to the phosphorylation of c-Jun (a component of AP-1) and that NOR pre-treatments at 10 and $30 \mu \mathrm{mol} / \mathrm{L}$ concentrations showed down-regulation of c-Jun activation with inhibitory percentages of $53.5 \%$ and $53.8 \%$, respectively (Figure 7B).

Effects of specific inhibitors for p38 MAPK, ERK, AKT, and AP-1 on IL-1 $\beta$-induced RANKL, IL-6, PGE $_{2}$, and MMP-13 expressions in FLS from AIA rats

To further verify the signaling pathway involved in the suppression of NOR, the effects of specific inhibitors for p38 MAPK, ERK, AKT, and AP-1 on IL-1 $\beta$-induced RANKL, IL-6, $\mathrm{PGE}_{2}$, and MMP-13 expressions were investigated (Figure 8). At concentrations of 5 and $10 \mu \mathrm{mol} / \mathrm{L}, \mathrm{SB} 203580$ (p38 MAPK inhibitor), U0126 (ERK inhibitor), triciribine (AKT inhibitor) and curcumin (AP-1 inhibitor) treatments reduced the levels of RANKL, IL-6, PGE 2 , and MMP-13 in the supernatants of FLS induced by IL-1 $\beta$. Therefore, p38 MAPK, ERK, AKT, and AP-1 are possibly associated with the suppressive effect of NOR on RANKL, IL-6, PGE 2 , and MMP-13 expressions.

\section{Discussion}

Radix Linderae has a long history of use for the treatment of rheumatoid-related diseases in the practice of traditional Chinese medicine. As the main active constituent of this herb medicine, NOR has previously been demonstrated to posses an anti-RA potential ${ }^{[9,10]}$. In the present study, the rat AIA model was used to evaluate the joint-protective effects of NOR. DEX, one type of adrenal cortex hormone drugs that has been used for the clinical treatment of RA for many years, was used as a positive control ${ }^{[27-30]}$. NOR and DEX were orally administered once daily for ten days starting from the time AIA was initiated in rats. Both exhibited substantial alleviation of the edema in either inoculated or non-inoculated paws, according to arthritis index scores. NOR but not DEX treatment significantly elevated the body weights of AIA rats. Radiological scanning results revealed that NOR (15 and $30 \mathrm{mg} / \mathrm{kg}$ ) treatments showed significant reduction of joint destruction in AIA rats. Histological assessments further revealed that the ankle joints from AIA rats were abnormal, as evidenced by pronounced synovial hyperplasia and inflammation as well as extensive erosive changes in the bone and cartilage, and NOR notably inhibited joint bone and cartilage erosion with a lower efficacious dose than that required for ameliorating synovial inflammation.

Although the precise pathogenesis and etiology of RA are not yet completely understood, substantial data have demonstrated that the progressive destruction of cartilage and bone in RA mainly results from elevated proinflammatory cytokine expressions, synovial neovascularization, proteinase-mediated dissolution of articular cartilage matrix and osteoclast-mediated subchondral bone resorption ${ }^{[31]}$.

It is widely accepted that the RANKL/OPG system plays an important role in the destruction of joints in RA by regulating the differentiation, survival and function of osteoclasts ${ }^{[32,33]}$, which could create resorption pits and local bone destruction via the degradation of the bone matrix and calcium solubilization $^{[17,18]}$. RANKL belongs to the tumor necrosis factor (TNF) family and may be detected as a secreted factor as a consequence of proteolytic cleavage. As a ligand, RANKL interacts with its receptor RANK, a type I transmembrane 

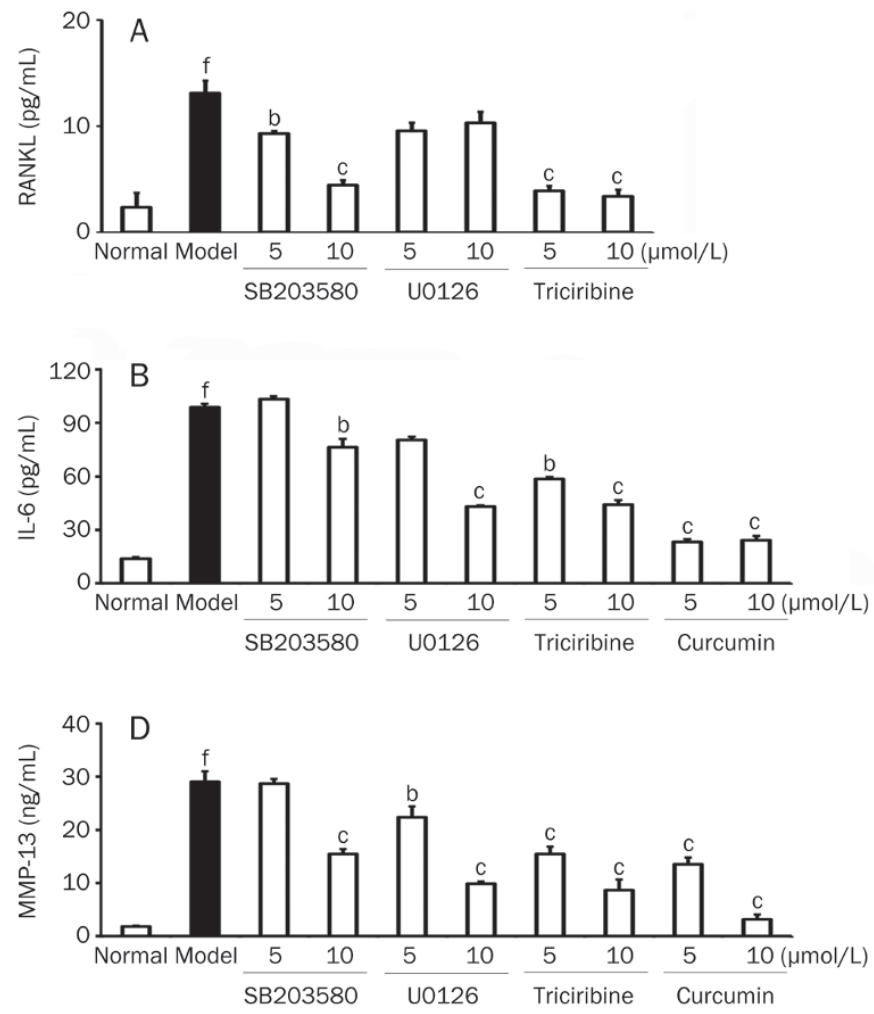
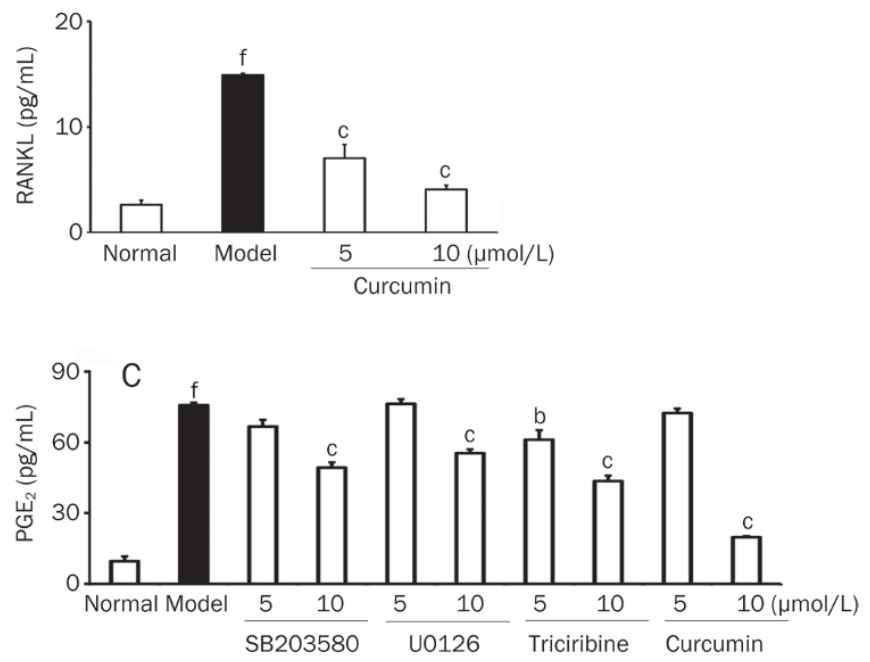

Figure 8. Effects of specific inhibitors for p38 MAPK, ERK, AKT, and AP-1 on IL-13-induced RANKL (A), IL-6 (B), PGE 2 (C), and MMP-13 (D) expressions in fibroblast-like synoviocytes (FLS) from adjuvant-induced arthritis rats. FLS were treated with SB203580 (a specific inhibitor of p38 MAPK, 5 and 10 $\mu \mathrm{mol} / \mathrm{L}$ ), U0126 (a specific inhibitor of ERK, 5 and $10 \mu \mathrm{mol} / \mathrm{L}$ ), triciribine (a specific inhibitor of AKT, 5 and $10 \mu \mathrm{mol} / \mathrm{L}$ ) or curcumin (a specific inhibitor of AP-1, 5 and $10 \mu \mathrm{mol} / \mathrm{L})$ in the presence or absence of IL-1B (10 ng/mL) for $72 \mathrm{~h}$, and the secretion of RANKL was measured by ELISA. FLS were treated with SB203580, U0126, triciribine, curcumin ( 5 and $10 \mu \mathrm{mol} / \mathrm{L})$ in the presence or absence of IL-13 (10 ng/mL) for $24 \mathrm{~h}$, and the secretion of IL-6, PGE 2 , and MMP-13 were measured by ELISA. Mean \pm SEM. $n=3 .{ }^{b} P<0.05,{ }^{\mathrm{C}} P<0.01$ vs model. ${ }^{\mathrm{f}} P<0.01$ vs normal.

receptor present on marrow monocytes and macrophages, inducing their differentiation into osteoclasts ${ }^{[34,35]}$. RANKL is becoming a novel target molecule for anti-RA remedy. Denosumab, an investigational and fully human monoclonal antibody with a high affinity and specificity for RANKL, can inhibit structural damage in patients with RA when added to ongoing methotrexate treatment $t^{[36,37]}$. In contrast, OPG belongs to the TNF-receptor super family, and it negatively regulates the activation and development of osteoclasts by sequestering its ligand RANKL ${ }^{[38]}$. In this study, NOR was demonstrated to reduce serum levels of RANKL but not OPG in AIA rats, markedly decreasing the ratio of RANKL/OPG. Furthermore, the mRNA levels of RANKL in the synovial membranes of AIA rats were also down-regulated by NOR (15 and $30 \mathrm{mg} / \mathrm{kg})$ and DEX $(0.5 \mathrm{mg} / \mathrm{kg})$ treatments. These findings indicated that the anti-joint destruction action of NOR in AIA rats was related to the down-regulation of RANKL levels. Matrix metalloproteinases (MMPs) are a large group of enzymes that play crucial roles in tissue remodeling and in the destruction of cartilage and bone in arthritic joints due to their ability to degrade a wide variety of extracellular matrix components. MMP-1, which is mainly synthesized by chondrocytes and fibroblasts in joint tissues afflicted with RA, is the most abundant member of the MMP-family, while MMP-13 efficiently cleaves the major component of the cartilage matrix type II collagen. MMP-1 and MMP-13 are both overexpressed in inflammatory arthritis cartilage and rate-limit the process of collagen degradation ${ }^{[39,40]}$. Cyclooxygenase (COX)-dependent prostaglandin $\mathrm{E}_{2}\left(\mathrm{PGE}_{2}\right)$, the major prostaglandin found in the synovial fluid of RA patients, is also closely associated with the remodeling of cartilage and bone. It can directly degrade proteoglycan in cartilage and bone matrix ${ }^{[41]}$. Moreover, the proinflammatory cytokine IL-6 causes bone resorption by inducing osteoclast formation via the induction of RANKL in synovial cells and cartilage degeneration by producing MMPs in the synovial cells and chondrocytes of RA joints. IL-6 receptor antibody tocilizumab (TCZ) monotherapy for 52 weeks showed significant improvement in the radiographic change of RA patients ${ }^{[42,43]}$. In our study, NOR treatments showed significant down-regulation of IL-6, PGE 2 , and MMP-13 but not MMP-1 levels in serum. RT-PCR results further revealed that NOR treatments suppressed the mRNA levels of IL-6, COX-2, and MMP-13 in the synovial membranes of AIA rats.

In RA, one of the most striking features is the hyperplasia of FLS in the layer lining of an affected joint. The tumor-like proliferation of RA-FLS is considered to be one of the major effectors of cartilage and bone destruction in RA. They have the ability to produce massive amounts of pro-inflammatory 
mediators and degradative enzymes, including RANKL, OPG, IL-6, MMPs, and PGE $_{2}$, which produce a marked effect by directly degrading joint matrix or binding to specific receptors. This leads to gene transcription and the formation of complicated signaling interactions that contribute to the progression of inflammatory arthritis ${ }^{[20-22,26]}$. Therefore, FLS cells were isolated from AIA rats and used in the following studies. In a previous study, we demonstrated that NOR inhibited IL-1 $\beta$-stimulated the production of IL-6 in the FLS of AIA rats. In this study, our results further showed that IL-1 $\beta$ stimulation resulted in significantly increased expressions of RANKL, $\mathrm{PGE}_{2}$ and MMP-13 in FLS and that NOR treatments suppressed the expressions of RANKL, $\mathrm{PGE}_{2}$, and MMP-13 in FLS.

To elucidate the underlying mechanisms by which NOR down-regulated the expression of inflammatory factors and enzymes, related signaling pathways were addressed. Generally, IL-1 $\beta$ functions through binding with its specific receptor IL-1RI and induces the recruitment of signaling-adaptor molecule TRAF6. The latter can lead to the activation of MAPKs, JAK/STAT, AKT, and NF-KB and the up-regulation of transcription factor AP-1 and others, which play an important regulatory role in the expression of inflammatory mediators ${ }^{[25,26,31]}$. In previous studies, we have demonstrated that NOR could inhibit IL-1 $\beta$-induced phosphorylation of p38 MAPK and ERK in FLS from AIA rats. In this study, we further assessed its effects on the IL-1 $\beta$-induced recruitment of TRAF6 and the activation of JAK2, STAT3, and AKT. The results showed that NOR did not interfere with the rapid recruitment of TRAF6 or the activation of downstream molecules JAK2 and STAT3 but that it inhibited the activation of AKT. On the other hand, specific inhibitors of p38 MAPK, ERK and AKT could reduce IL- $1 \beta$-induced production of RANKL, IL-6, PGE 2 , and MMP-13 in FLS. It was postulated that p38 MAPK, ERK, and AKT might be targets for NOR in reducing the production of inflammatory mediators.

Both NF-kB and AP-1, two transcription factors, are critical regulators of cytokine production ${ }^{[4]}$. Previously, NOR was shown to slightly affect the activation of the NF-KB pathway. In the present study, its effect on the activation of AP-1 was tested. AP-1 belongs to the class of basic leucine zipper (bZIP) transcription factors. Its activity can be markedly increased in synoviocytes as a response to the stimulation of cytokines, such as IL-1 $\beta$ and TNF- $\alpha$, through MAPK, AKT, and other signaling pathways ${ }^{[45-48]}$. By binding to AP-1 motifs in the promoters of the relative genes, AP- 1 controls the expression of MMPs, aggrecanase, cysteine proteases and pro-inflammatory cytokines, which are all primary mediators that mediate joint destruction. It is worth noting that the expression of MMPs in FLS is AP-1-dependent, and AP-1 inhibitors can reduce the production of most of matrix-degrading MMPs, including MMP-3, 9, and 13, as well as inflammatory cytokines ${ }^{[44,45]}$. In the current study, NOR significantly inhibited the activation of c-Jun (a component of AP-1) in IL-1 $\beta$-stimulated FLS. Curcumin, a specific inhibitor of AP-1, was shown to dramatically down-regulate the expressions of RANKL, IL-6, PGE 2 , and
MMP-13. In addition, the activation of MAPKs and AKT in FLS was also suppressed by NOR treatments. These findings suggested that NOR might reduce the expressions of RANKL, IL-6, PGE $_{2}$, and MMP-13 by preventing the activation of AP-1 via down-regulation of MAPK and AKT pathways.

Taken together, the present study demonstrates that NOR could markedly protect joints from destruction in AIA rats. The joint-protective mechanisms of NOR could be mainly attributed to the down-regulation of RANKL, IL-6, $\mathrm{PGE}_{2}$, and MMP-13 expression. The p38 MAPK/ERK/AKT/AP-1 pathways were closely involved in the inhibitory effect of NOR. NOR is a potential candidate drug for RA and other diseases characterized by excessive joint destruction.

\section{Acknowledgements}

This work was supported by the Specialized Research Fund for the Doctoral Program of Higher Education (No 20090096110007), the Innovative Training Plan for Graduate Students of Jiangsu Province (CXLX12_0326) and the Priority Academic Program Development of Jiangsu Higher Education Institutions, and it was partially funded by the Program for Changjiang Scholars and Innovative Research Team in University (IRT1193).

\section{Author contribution}

Zhi-feng WEI carried out all in vivo studies, performed the analysis of collected data and drafted the manuscript; Xiao-lan JIAO, Ting WANG, and Qian LU executed the in vitro studies; and Yu-feng XIA, Zheng-tao WANG, Qing-long GUO, Gui-xin $\mathrm{CHOU}$, and Yue DAI conducted the analyses.

\section{References}

1 Ngian GS. Rheumatoid arthritis. Aus Fam Physician 2010; 39: 626-8.

2 Karmakar S, Kay J, Gravallese EM. Bone damage in rheumatoid arthritis: mechanistic insights and approaches to prevention. Rheum Dis Clin North Am 2010; 36: 385-404.

3 Goldring SR. Bone and joint destruction in rheumatoid arthritis: what is really happening? J Rheumatol 2002; 65: 44-8.

4 Carmona L, Cross M, Williams B, Lassere M, March L. Rheumatoid arthritis. Best Pract Res Clin Rheumatol 2010; 24: 733-45.

5 Yang CL, Or TC, Ho MH, Lau AS. Scientific basis of botanical medicine as alternative remedies for rheumatoid arthritis. Clin Rev Allergy Immunol 2012. doi: 10.1007/s12016-012-8329-8.

6 Zhao J, Zha Q, Jiang M, Cao H, Lu A. Expert consensus on the treatment of rheumatoid arthritis with Chinese patent medicines. J Altern Complement Med 2012. doi: 10.1089/acm.2011.0370.

7 Zhao XX, Peng C, Zhang H, Qin LP. Sinomenium acutum: A review of chemistry, pharmacology, pharmacokinetics, and clinical use. Pharm Biol 2012; 50: 1053-61.

8 Wang C, Dai Y, Yang J, Chou G, Wang C, Wang Z. Treatment with total alkaloids from Radix Linderae reduces inflammation and joint destruction in type II collagen-induced model for rheumatoid arthritis. J Ethnopharmacol 2007; 111: 322-8.

9 Luo Y, Liu M, Dai Y, Yao X, Xia Y, Chou G, et al. Norisoboldine inhibits the production of pro-inflammatory cytokines in lipopolysaccharidestimulated RAW 264.7 cells by down-regulating the activation of MAPKs but not NF-KB. Inflammation 2010; 33: 389-97. 
10 Wei Z, Wang F, Song J, Lu Q, Zhao P, Xia Y, et al. Norisoboldine inhibits the production of interleukin- 6 in fibroblast-like synoviocytes from adjuvant arthritis rats through PKC/MAPK/NF-KB-p65/CREB pathways. J Cell Biochem 2012; 113: 2785-95.

11 Chou GX, Norio N, Ma CM, Wang ZT, Masao H. Isoquinoline alkaloids from Lindera aggregata. Chin J Nat Med 2005; 5: 272-5.

12 Jawed H, Shah SU, Jamall S, Simjee SU. N-(2-hydroxy phenyl) acetamide inhibits inflammation-related cytokines and ROS in adjuvantinduced arthritic (AIA) rats. Int Immunopharmacol 2010; 10: 900-5.

13 Yifan W, Dengming W, Zheng L, Yanping L, Junkan S. Triptolide inhibits CCR5 expressed in synovial tissue of rat adjuvant-induced arthritis. Pharmacol Rep 2007; 59: 795-9.

14 Nagai N, Fukuhata T, Ito Y, Usui S, Hirano K. Preventive effect of coadministration of water containing magnesium ion on indomethacin induced lesions of gastric mucosa in adjuvant-induced arthritis rat. Biol Pharm Bull 2009; 32: 116-20.

15 Zhu L, Wei W, Zheng YQ, Jia XY. Effects and mechanisms of total glucosides of paeony on joint damage in rat collagen-induced arthritis. Inflamm Res 2005; 54: 211-20.

16 Wang QT, Zhang LL, Wu HX, Wei W. The expression change of $\beta$-arrestins in fibroblast-like synoviocytes from rats. J Ethnopharmacol 2011; 133: 511-6.

17 Pettit AR, Walsh NC, Manning C, Goldring SR, Gravallese EM. RANKL protein is expressed at the pannus-bone interface at sites of articular bone erosion in rheumatoid arthritis. Rheumatology (Oxford) 2006; 45: 1068-76.

18 Schett G. Cells of the synovium in rheumatoid arthritis. Osteoclasts Arthritis Res Ther 2007; 9: 203.

19 Huh JE, Hong JM, Baek YH, Lee JD, Choi DY, Park DS. Antiinflammatory and anti-nociceptive effect of Betula platyphylla var. japonica in human interleukin-1ß-stimulated fibroblast-like synoviocytes and in experimental animal models. J Ethnopharmacol 2011; 135: 126-34.

20 Giuliani N, Morandi F, Tagliaferri S, Rizzoli V. Targeting pathways mediating bone disease. Curr Pharm Biotechnol 2006; 7: 423-9.

21 Blair JM, Zheng Y, Dunstan CR. RANK ligand. Int J Biochem Cell Biol 2006; 39: 1077-81.

22 Bartok B, Firestein GS. Fibroblast-like synoviocytes: key effector cells in rheumatoid arthritis. Immunol Rev 2010; 233: 233-55.

23 Kay J, Calabrese L. The role of interleukin-1 in the pathogenesis of rheumatoid arthritis. Rheumatology (Oxford) 2004; 43: 2-9.

24 Rossa C, Ehmann K, Liu M, Patil C, Kirkwood KL. MKK3/6-p38 MAPK signaling is required for IL-1beta and TNF-alpha-induced RANKL expression in bone marrow stromal cells. J Interferon Cytokine Res 2006; 26: 719-29.

25 Tang ZN, Zhang F, Tang P, Qi XW, Jiang J. Hypoxia induces RANK and RANKL expression by activating HIF-1 $\alpha$ in breast cancer cells. Biochem Biophys Res Commun 2011; 408: 411-6.

26 Wang JH, Shih KS, Liou JP, Wu YW, Chang AS, Wang KL, et al. Antiarthritic effects of magnolol in human interleukin $1 \beta$-stimulated fibroblast-like synoviocytes and in a rat arthritis model. PLoS One 2012; 7: e31368.

27 Teramachi J, Kukita A, Li YJ, Ushijima Y, Ohkuma H, Wada N, et al. Adenosine abolishes MTX-induced suppression of osteoclastogenesis and inflammatory bone destruction in adjuvant-induced arthritis. Lab Invest 2011; 91: 719-31.

28 Lubahn C, Schaller JA, Shewmacker E, Wood C, Bellinger DL, Byron D, et al. Preclinical efficacy of sodium narcistatin to reduce inflammation and joint destruction in rats with adjuvant-induced arthritis. Rheumatol Int 2012; 32: 3751-60.
29 Cuzzocrea S, Mazzon E, Paola RD, Genovese T, Muià C, Caputi AP, et al. Effects of combination M40403 and dexamethasone therapy on joint disease in a rat model of collagen-induced arthritis. Arthritis Rheum 2005; 52: 1929-40.

30 Islander U, Jochems C, Stubelius A, Andersson A, Lagerquist MK, Ohlsson $\mathrm{C}$, et al. Combined treatment with dexamethasone and raloxifene totally abrogates osteoporosis and joint destruction in experimental postmenopausal arthritis. Arthritis Res Ther 2011; 13: R96.

31 Gravallese EM. Bone destruction in arthritis. Ann Rheum Dis 2002; 61: ii84-6.

32 Okamoto K, Takayanagi $\mathrm{H}$. Osteoclasts in arthritis and Th17 cell development. Int Immunopharmacol 2011; 11: 543-8.

33 Broadhead ML, Clark JC, Dass CR, Choong PF, Myers DE. Therapeutic targeting of osteoclast function and pathways. Expert Opin Ther Targets 2011; 15: 169-81.

34 Wilson TJ, Nannuru KC, Futakuchi M, Sadanandam A, Singh RK. Cathepsin $\mathrm{G}$ enhances mammary tumor-induced osteolysis by generating soluble receptor activator of nuclear factor-kappaB ligand. Cancer Res 2008; 68: 5803-11.

35 Blair HC, Zaidi M. Osteoclastic differentiation and function regulated by old and new pathways. Rev Endocr Metab Disord 2006; 7: 23-32.

36 Lewiecki EM. Denosumab for joints and bones. Curr Rheumatol Rep 2009; 11: 196-201.

37 Sharp JT, Tsuji W, Ory P, Harper-Barek C, Wang H, Newmark R. Denosumab prevents metacarpal shaft cortical bone loss in patients with erosive rheumatoid arthritis. Arthritis Care Res (Hoboken) 2010; 62: $537-44$.

38 Neumann E, Gay S, Müller-Ladner U. The RANK/RANKL/osteoprotegerin system in rheumatoid arthritis: new insights from animal models. Arthritis Rheum 2005; 52: 2960-7.

$39 \mathrm{Ha}$ MK, Song YH, Jeong SJ, Lee HJ, Jung JH, Kim B, et al. Emodin inhibits proinflammatory responses and inactivates histone deacetylase 1 in hypoxic rheumatoid synoviocytes. Biol Pharm Bull 2011; 34: 1432-7.

40 Chang Y, Wei W, Zhang L, Xu HM. Effects and mechanisms of total glucosides of paeony on synoviocytes activities in rat collagen-induced arthritis. J Ethnopharmacol 2009; 121: 43-8.

41 Hardy MM, Seibert K, Manning PT, Currie MG, Woerner BM, Edwards $D$, et al. Cyclooxygenase 2-dependent prostaglandin $E_{2}$ modulates cartilage proteoglycan degradation in human osteoarthritis explants. Arthritis Rheum 2002; 46: 1789-803.

42 Hashizume M, Mihara M. The roles of interleukin- 6 in the pathogenesis of rheumatoid arthritis. Arthritis 2011; 2011: 765624.

43 Ryu JH, Yang S, Shin Y, Rhee J, Chun CH, Chun JS. Interleukin-6 plays an essential role in hypoxia-inducible factor $2 \alpha$-induced experimental osteoarthritic cartilage destruction in mice. Arthritis Rheum 2011; 63: $2732-43$.

44 Shiozawa S, Tsumiyama K. Pathogenesis of rheumatoid arthritis and c-Fos/AP-1. Cell Cycle 2009; 8: 1539-43.

45 Handel ML, Girgis L. Transcription factors. Best Pract Res Clin Rheumatol 2001; 15: 657-75.

46 Yamanishi Y, Firestein GS. Pathogenesis of rheumatoid arthritis: the role of synoviocytes. Rheum Dis Clin North Am 2001; 27: 355-71.

47 Han Z, Boyle DL, Chang L, Bennett B, Karin M, Yang L, et al. c-Jun $\mathrm{N}$-terminal kinase is required for metalloproteinase expression and joint destruction in inflammatory arthritis. J Clin Invest 2001; 108: 73-81.

48 Hazeki K, Nigorikawa K, Hazeki O. Role of phosphoinositide 3-kinase in innate immunity. Biol Pharm Bull 2007; 30: 1617-23. 